\title{
ANALYSIS OF RELIABILITY OF THE DRILL PIPE IN THE CLAMPING MECHANISM
}

\author{
Emin Musa Afandiyev \\ Department of Engineering and Applied Science ${ }^{l}$ \\ Mahammadali Nuraddin Nuriyev $\bowtie$ \\ Department of Engineering and Applied Science ${ }^{l}$ \\ mehman62@mail.ru \\ ${ }^{1}$ Azerbaijan State Ekonomic University (UNEC) \\ 6 Istiglaliyyat str., Baku, Azerbaijan, AZ 1001
}

$\triangle$ Corresponding author

\begin{abstract}
In oilfield equipment, a significant place is occupied by clamping mechanisms used to grip pipes during tripping operations. They are mainly divided into 2 groups. The first includes mechanisms with a forced clamping of the part. The second group includes self-clamping devices with a wedge mechanism. Here, the clamping force increases in proportion to the axial shear force. In these clamping devices, clamping jaws serve as a common element. In addition to smooth jaws, there may be jaws with notches on the inner cylindrical surface. Such notches contribute to an increase in the coefficient of adhesion when clamping cylindrical parts, in particular pipes. During the operation of clamping devices with corrugated jaws, the teeth of the notch are introduced into the pipe walls under the action of the clamping force. The shearing force can then displace the pipe relative to the jaws. The adhesion coefficient $\mu$ is the ratio of the shear force $P$ to the clamping force $Q$, i. e. $P / Q$. Exceeding the shear force $P$ of the limit value causes the pipe to be clamped to move. The correct choice of the place of load application is also of great importance.

Optimum clamping performance can be achieved by clamping workpieces without slipping from shear forces. At the same time, it is necessary to ensure reliability, efficiency, productivity. Therefore, all factors that determine the holding capacity of clamping mechanisms should be considered. These factors include the coefficient of adhesion, the design of the working surfaces of the clamping elements, the type of notch of the corrugated jaws and the place of application of the clamping force.
\end{abstract}

Keywords: holding capacity, drill pipe, clamping mechanism, string weight, clamping area.

DOI: $10.21303 / 2461-4262.2021 .001765$

\section{Introduction}

The factors influencing the quality of drill pipes in the clamping mechanism during operation are considered. Pipes are subject to elastic and plastic deformation. They are subjected to high loads from clamping forces, as well as axial tensile forces from the weight of the column. Therefore, increased requirements are imposed on the reliability of pipes. Experiments were carried out to establish the effect of the load application on the stresses and deformations of cylindrical thin-walled parts.

Practice shows that wedge grips used in round-trip operations are widely used in the oilfield business. Significant loads acting both on the wedge grips and on the pipes being clamped place high demands on their holding capacity. The elimination of accidents associated with the breakage of a string at the rig requires significant resources. This explains the relevance of the presented work.

The holding capacity of the wedge grip is related to the magnitude and nature of the stresses and deformations arising in the section of the pipe at the point of its grip. The correct choice of the area for fixing cylindrical parts will reduce deformation during operation. An important role is played by the methodology for calculating the maximum permissible weight of the pipe string. To achieve this aim, the following objectives were set:

a) determine the effect of the place of application of the clamping force on the stress state of the cylindrical part in the clamping mechanism,

b) improve the methodology for calculating the maximum permissible weight of a pipe string during tripping operations while drilling oil and gas wells. 


\section{Literature review and problem statement}

The high labor intensity and energy intensity of the oil production process make increased demands on the quality of drilling equipment, in particular, clamping mechanisms and drill pipes. Extending the service life of drill pipes minimizes the occurrence of emergencies. Therefore, work in this direction is of great practical importance.

In work [1], the design features of clamping devices used in round-trip operations when drilling wells are considered. However, not enough attention has been paid to damage to the outer surface of the pipe by clamping jaws.

In work [2] it is shown that the state of the pipe in the clamping device is influenced by various factors, such as radial and axial loads, clamping force, column mass, place of load application. It is noted that the most optimal operation of the clamping jaws is characterized by an oblique intersecting notch, which provides a high holding capacity of the clamping mechanisms.

Scientific research on the operation of clamping mechanisms with oilfield pipes has also been carried out at the American Petroleum Institute (API). In these works, it was noted that deformations of drill pipes occur due to cuts, which are left by the teeth of the clamping jaws of the drill tongs or wedge grips [3].

Work [4] is devoted to the study of the influence of external factors on the stress state of the pipe. The analysis of adhesion coefficients in clamping devices is given. Methods for improving their elements in order to increase the adhesion coefficients are described. Methods for improving the design of their elements are proposed in order to increase the adhesion coefficients.

Other works have also investigated the effect of clamping device design elements on the stress state and deformation of the pipe, and recommendations are given for improving their design in order to increase the holding capacity. A method of surface hardening is proposed to increase the service life of drill pipes [5-7].

In works $[8,9]$ it is noted what deformations the pipe is subject to during operation. The reasons for material creep are considered, which can be a consequence of stress relaxation under prolonged action of significant stresses. The process of stress relaxation and models for their determination and accounting are considered in [9]. These processes show that in order to increase the holding capacity of clamping devices, it is necessary to comprehensively study all the factors that affect the deformation of the drill pipe during tripping operations.

In studies $[10,11]$, attention is paid to the issues of safe operation of the pipe string during tripping operations.

Despite the extensive literature on this topic, many problems related to the behavior of drill pipes during tripping operations still await their solution. Insufficient attention is paid to recommendations for reducing stresses and deformations when fastening thin-walled cylindrical and other similar parts in clamping devices. There are practically no dependencies for calculations and analysis of loading schemes.

Reliability and durability of clamping devices when working with thin-walled cylindrical parts is of great importance, both in mechanical engineering and in the oil and gas industry. Therefore, studying the issues of increasing the holding capacity of clamping mechanisms and reducing pipe deformations is an urgent task.

\section{The aim and objectives of research}

The aim of this research is to determine the possibility of increasing the holding capacity of wedge grips and other clamping mechanisms in different conditions of work with cylindrical parts.

To achieve this aim, it is necessary to solve the following objectives:

- to determine the influence of the place of application of the clamping force on the stress state of the cylindrical part in the clamping mechanism;

- to improve the methodology for calculating the maximum permissible weight of a pipe string during tripping operations while drilling oil and gas wells. 


\section{Materials and methods of research}

\section{1. Analysis of the place of load application}

An analysis of the influence of the place of action of clamping forces on the value of the maximum radial deformation of thin-walled cylindrical parts was carried out using an experimental research method.

The hypothesis was the idea that the place of application of the clamping load plays a significant role in the magnitude of the radial deformation of the cylindrical part. An experiment was carried out using a specially designed pipe-clamping chuck for clamping the part (Inventor's Certificate No. 910370) Fig. 1. When clamping the parts, the chuck pads are closed and the pipe is pre-clamped. When the pipe is screwed in, it rotates under the action of a torque, and an additional clamping of the pipe occurs.

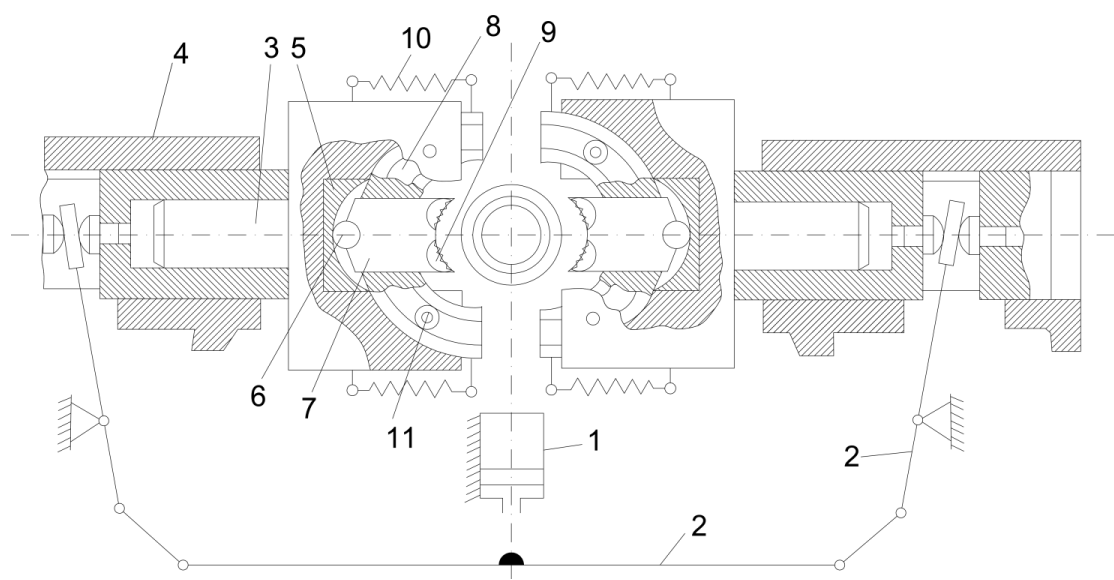

Fig. 1. Pipe-clamping chuck

The maximum radial deformation of the pipe as a result of the action of a uniformly distributed annular load $Q$ applied at the end of the pipe is determined by the formula:

$$
W_{\max }=\frac{Q}{2 \beta^{3} D},
$$

where $\beta$ - angle of coverage with one jaw (Fig. 2).

With a load applied in the middle part of the pipe at a distance $C \geq 3 / 4 \cdot \pi / \beta=L / 2 \beta$ from the end, the deformation is equal to:

$$
W_{\max c p}=\frac{Q}{8 \beta^{3} D},
$$

where $L$ - the limiting deformation zone.

Comparison of the values of the maximum deformations, which are determined by expressions (1), (2), indicates that with distance from the end face of the place of application of the load $Q$, the maximum deformation decreases, which reaches a minimum at $C \geq \pi / 2 \beta \approx 1.6 / \beta \approx L_{1}$ and remains equal $Q / 8 \beta^{3} D$. In this case, a decrease in deformation is possible by 4 times.

The maximum radial deformation of a cylindrical part of small length (rings, bushings, sleeves) under the action of an annular force $Q$ applied in the end section is equal to:

$$
W_{\max a v}=\frac{Q}{8 \beta^{3} D} k_{1}
$$

applied in the middle of the cylinder is equal to:

$$
W_{\max a v}=\frac{Q}{8 \beta^{3} D} k_{2},
$$

where $k_{1}$ and $k_{2}$ are coefficients depending on the length of the short cylinder, given in Table 1 . 
Table 1

Auxiliary data for the transition from long cylindrical parts to short

\begin{tabular}{ccccccccccc}
\hline $\boldsymbol{\beta} \boldsymbol{l}_{\mathbf{1}}$ & $\mathbf{0 . 4}$ & $\mathbf{0 . 6}$ & $\mathbf{0 . 8}$ & $\mathbf{1 . 0}$ & $\mathbf{1 . 2}$ & $\mathbf{1 . 4}$ & $\mathbf{1 . 7}$ & $\mathbf{2 . 0}$ & $\mathbf{3 . 0}$ & $\mathbf{6 . 0}$ \\
\hline$K_{1}$ & 4.990 & 3.310 & 2.507 & 2.019 & 1.699 & 1.479 & 1.265 & 1.137 & 1.007 & 1.000 \\
$K_{2}$ & 1.601 & 1.406 & 1.228 & 1.079 & 0.975 & 0.921 & 0.915 & 0.946 & 1.000 & 1.000
\end{tabular}

Here $\beta l_{1}$ - the reduced length of the short cylindrical part.

According to the above formulas (3), (4) and the data in Table 1, the ratios $W_{\max e n d} / W_{\max }$ av are determined depending on the reduced length of the short part $\beta l_{1}$ (Table 2).

Table 2

Reduction of deformations of a short cylindrical part of length $\beta l_{1}$ when it is fixed in the middle

\begin{tabular}{ccccccccccc}
\hline $\boldsymbol{\beta} \boldsymbol{l}_{\mathbf{1}}$ & $\mathbf{0 . 4}$ & $\mathbf{0 . 6}$ & $\mathbf{0 . 8}$ & $\mathbf{1 . 0}$ & $\mathbf{1 . 2}$ & $\mathbf{1 . 4}$ & $\mathbf{1 . 7}$ & $\mathbf{2 . 0}$ & $\mathbf{3 . 0}$ & $\mathbf{6 . 0}$ \\
\hline$W_{\text {end }} / W_{\text {av }}$ & 12.5 & 9.45 & 8.2 & 7.5 & 7.0 & 6.43 & 5.55 & 4.8 & 4.028 & 4.0
\end{tabular}

When clamping short cylinders (rings, sleeves), clamping forces should be applied not at the end, but in the middle of the workpiece being clamped. In this case, the maximum deformations are reduced up to 10 times. With a decrease in the length of the part $\beta l_{1}$, the reliability of fixing in the middle part increases.

In existing clamping mechanisms, the clamping force is distributed over the area. To check the optimal choice of the place for fixing the pipe in the mechanism that provides a uniformly distributed load on the section $l_{i}, 2$ options are possible:

1. Uniformly distributed load acts at the end on the length $l_{i}$, and the maximum value of the radial deformation is obtained in the section at the end $W_{\max }$ end $l i$.

2. Uniformly distributed load acts on the same length $l_{i}$ in the middle part of the part. And the maximum radial deformation $W_{\max a v}$ i is observed in the middle of the section where the force is applied.

The results of comparison of the maximum deformations $W_{\max \text { end } l i}$ and $W_{\max \text { av } l i}$ arising at different lengths of the loading section $\beta l_{1}$ are given in Table 3.

Table 3

Reducing pipe deformations when fixing it in the middle part

\begin{tabular}{cccccccccc}
\hline $\boldsymbol{\beta} \boldsymbol{l}_{\mathbf{1}}$ & $\mathbf{0 . 2}$ & $\mathbf{0 . 4}$ & $\mathbf{1}$ & $\mathbf{1 . 4}$ & $\mathbf{2}$ & $\mathbf{2 . 6}$ & $\mathbf{3}$ & $\mathbf{4}$ & $\mathbf{7}$ \\
\hline$W_{\text {end } l i} / W_{\text {av } l i}$ & 3.61 & 3.26 & 2.37 & 1.94 & 1.47 & 1.24 & 1.10 & 0.95 & 0.97
\end{tabular}

It follows from the above table that when fixing a cylindrical part with a uniformly distributed load of $Q$ value over a length $\beta l_{1}$, it is advisable to use the clamping force in the middle part at a distance $l_{2} \geq 3 / 4 \cdot \pi / 4 \beta$ from the end.

\section{2. Calculation of the permissible load on the drill pipe}

With increasing drilling depths, special attention should be paid to calculating the maximum permissible pipe load. This is due to the fact that with a large weight, the risk of column breakage increases. To ensure reliable operation of the clamping device, it is necessary to determine the maximum load on the pipe. Such a load should not exceed the moving load. A method for calculating the permissible load on the drill pipe is proposed.

When selecting drill pipe strings, only axial load is taken into account, that is, weight. The obtained results of experimental studies made it possible to develop a methodology for calculating 
the maximum permissible weight of drill strings, taking into account the influence of some factors. The determination of the ultimate axial load on a pipe clamped in a wedge grip (Fig. 2) is carried out according to the formula [11]:

$$
P=\frac{\sigma F}{1+\frac{d_{a v}}{4 l \operatorname{tg}(\alpha+\varphi)}},
$$

where $F$ - cross-sectional area of the pipe; $\alpha$ - slope angle of the wedge; $\varphi$ - angle of friction between the outer surface of the wedges and the body; $l$-wedge length; $d_{a v}$-average diameter of the pipe section.

The safety factor is taken to $k=1.15-1.2$.

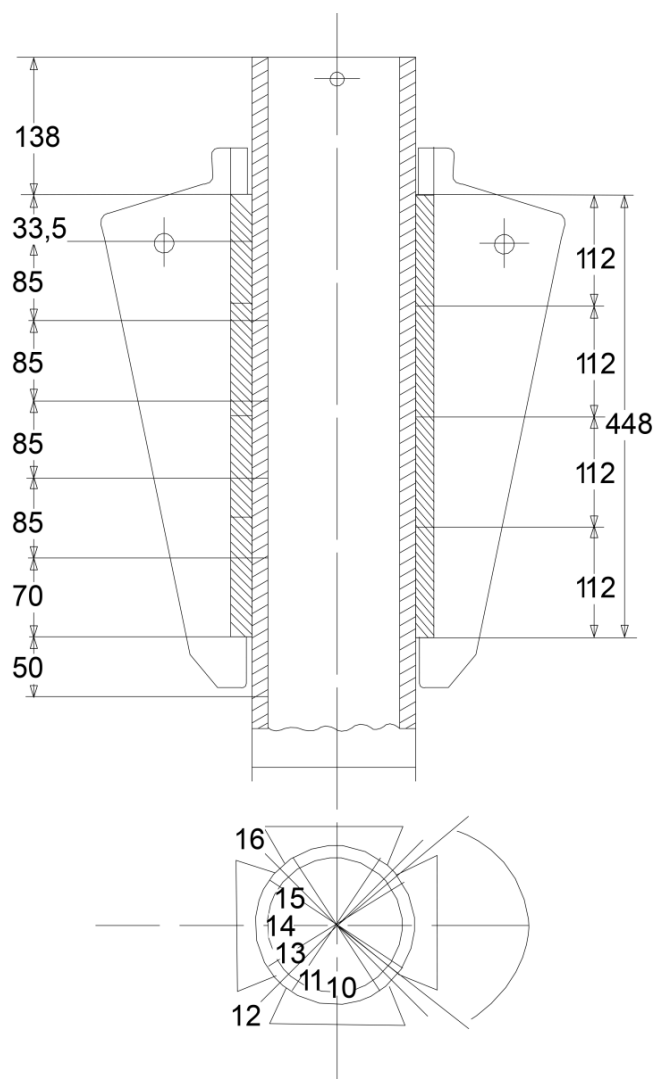

Fig. 2. Drill pipe in wedge grip

Fig. 2 shows the zone of action of the wedge grip on the pipe during the round trip operations.

Fig. 1 shows a chuck used to investigate the effect on deformation of a load location on short cylindrical parts.

Comparison of the results of ultimate loads, calculated using this formula, with experimental data obtained when determining stresses and strains in a drill pipe clamped in a wedge grip, showed that the above formula gives overestimated values of the permissible load.

When calculating the load, one should also take into account the error in the shape of the pipe, inaccuracy in the manufacture of parts of the clamping mechanism, incomplete coverage of the pipe with clamping jaws, etc. Taking into account the experimental data obtained, coefficients reflecting the actual conditions of clamping should be introduced into the above formula.

The maximum permissible load on a drill pipe clamped in a wedge grip with a uniformly distributed load should be determined by the formula, taking into account the coefficient $k$, taking into account the actual contact area of the jaws with the pipe: 


$$
P=\frac{\sigma F}{1+\frac{d_{a v}}{4 l \operatorname{tg}(\alpha+\varphi)}} \frac{1}{k_{1}},
$$

where $k$ - coefficient taking into account the actual contact area of the jaws with the pipe, $0.4-0.7$; $k_{1}$ - safety factor 1.2-1.6.

The ultimate load $P$ on the drill pipe clamped in a wedge grip with gaps between the jaws $>5^{\circ}$ should be calculated by the formula:

$$
P=\frac{\sigma F}{1+\frac{d_{a v} k_{3}}{4 l k k_{2} \operatorname{tg}(\alpha+\varphi)}} \frac{1}{k_{1}},
$$

where $k_{2}$ - coefficient that takes into account the actual angle of coverage of the pipe with jaws:

$$
k_{2}=\frac{n \beta}{360},
$$

where $\beta$ - angle of coverage with one jaw; $n$ - number of jaws along the perimeter; $k_{3}$ - coefficient characterizing the value of the bending moment in the section between the jaws in connection with a decrease in $\beta$;

$$
k_{3}=\frac{\eta_{1}}{\eta}
$$

where $\eta$ - coefficient characterizing the value of the bending moment in the section between the jaws $\left(\alpha=45^{\circ}\right) ; \eta$ - coefficient characterizing the value of the bending moment in the section $\alpha=45^{\circ}$ when clamping a part with a load evenly distributed along the perimeter.

$\eta$ is determined by the formula:

$$
\eta_{i}=\frac{1}{\pi}\left[\theta\left(1+2 \sin ^{2} \theta\right)+3 \sin \theta \cos \theta\right]-\sin \theta(\sin \alpha+\cos \alpha),
$$

where

$$
\theta=\frac{\beta}{2}
$$

Using the above formulas, it is possible to determine the permissible weights of drill strings for various sizes and strength groups of the pipe material. The values of the coefficients are determined according to the given method.

5. Results and discussion of the study of the state of the cylindrical part in the clamping mechanism, as well as the factors affecting the permissible weight of the drill string

In the process of clamping short cylindrical parts such as pipes, rings, sleeves, a radial load is exerted on them, causing deformations of the shape, which depend on the place of application of the load. The experiments carried out made it possible to compile tables of deformations of cylindrical parts in different places of action of clamping forces. Analysis of these tables shows that the smallest deformations occur when clamping parts in the middle part of a cylindrical part under the same radial loads. The results of the analysis show that thin-walled cylindrical parts (pipes, sleeves, rings) should be fixed not at the end, but in the middle part, so as in this case, the maximum deformation is less with the same clamping forces.

When clamping short cylinders (rings, sleeves), clamping forces should be applied not at the end, but in the middle of the workpiece being clamped. In this case, the maximum deformations are reduced up to 10 times. With a decrease in the length of the part, the reliability of fastening in the middle part increases. 
During tripping operations, at individual peak points, the compressive stresses exceed the pipe's yield point. These points are formed by repeatedly clamping the pipe in the same area, which can lead to an emergency. The existing calculation of the maximum permissible weight of a pipe string does not take into account factors that arise in real conditions, and gives overestimated values of permissible loads. Coefficients are entered into the calculation formula taking into account the actual clamping conditions.

The influence of the place of application of clamping forces on the value of the maximum radial deformation of thin-walled cylindrical parts is considered.

Based on the results of the experiments, tables of radial deformations of cylindrical parts are compiled for different variants of places of load application. The results of maximum deformations at different lengths of loading sections are compared. From the analysis carried out, it follows that the cylindrical parts must be fixed not at the end, but in the middle part, due to the fact that the maximum deformation in this case decreases with the same clamping forces.

The sources on deformations of thin-walled parts did not consider the question of the optimal place for applying a load to a short cylindrical part. Materials of cylindrical parts, grades of alloys and their physical and mechanical properties can be taken into account in further work. The complexity of this study is the need for extensive industrial testing. During tripping operations in a wedge grip, the drill or casing is subjected to multiple clamping in the same range. If, at individual peak points, the compressive stresses exceed the yield strength of the pipe, plastic deformation occurs at these points on the pipe surface. With a large number of clampings, plastic deformation manifests itself at different points of the pipe along the length and circumference, forming a decrease in the outer diameter of the pipe in this area. In this case, timely rejection of damaged pipes is necessary in order to avoid creating an emergency.

The existing method for calculating the maximum allowable weight of a pipe string does not take into account the factors that arise in practical conditions and gives overestimated values of the allowable loads. This can lead to pipe failure. Factors have been entered into the formula to take into account the actual clamping conditions.

In the future, industrial tests of new designs of elements of clamping devices should be carried out. These studies were conducted with drill pipes only, although the main findings can be applied to other types of pipes. The development of this study may consist in the application of the results for drill and casing pipes from different types of materials, alloy grades and physical and mechanical properties, and with the use of other types of loads.

\section{Conclusions}

On the stand simulating the operation of the wedge clamping device, experiments were carried out to determine the influence of the operating conditions of the clamping devices on the stress state of the clamped pipe during operation.

The results of the comparison of deformations show that short thin-walled cylindrical parts (pipes, sleeves, rings) should be fixed not at the end, but in the middle part. In this case, the maximum deformation is less with the same clamping forces. When clamping short cylinders (rings, sleeves), clamping forces should be applied not at the end, but in the middle part of the clamped part. In this case, the maximum deformations are reduced up to 10 times. With a decrease in the length of the part, the reliability of fastening in the middle part increases.

The method for calculating the maximum permissible weight of a pipe string has been improved. In practical terms, it is necessary to take into account such factors as the out-of-roundness of the pipe, inaccuracy in the manufacture of the elements of the clamping device and the associated incomplete coverage of the pipe with jaws. The calculation formula includes coefficients that take into account the actual clamping conditions.

\section{References}

[1] Markov, O., Gerasimenko, O., Khvashchynskyi, A., Zhytnikov, R., Puzyr, R. (2019). Modeling the techological process of pipe forging without a mandrel. Eastern-European Journal of Enterprise Technologies, 3 (1 (99)), 42-48. doi: https://doi.org/ $10.15587 / 1729-4061.2019 .167077$ 
[2] Afandiyev, E. M., Nuriyev, M. N. (2019). Studying the quality of drill pipes clamped in a wedge clamp. Eastern-European Journal of Enterprise Technologies, 4 (7 (100)), 16-21. doi: https://doi.org/10.15587/1729-4061.2019.174494

[3] Rukovodstvo po trubam neftyanogo sortamenta i ih soedineniyam, primenyaemym za rubezhom (1969). Moscow: Nedra, 296.

[4] Afandiyev, E. M., Nuriyev, M. N. (2020). Improving the retention capacity of clamping elements. Eastern-European Journal of Enterprise Technologies, 1 (1 (103)), 47-51. doi: https://doi.org/10.15587/1729-4061.2020.195193

[5] Wang, L., Guo, S., Gong, H., Shang, X. (2016). Research and development of a self-centering clamping device for deep-water multifunctional pipeline repair machinery. Natural Gas Industry B, 3 (1), 82-89. doi: https://doi.org/10.1016/j.ngib.2015.12.012

[6] Yakhin, A. R., Ismakov, R. A., Garifullin, R. R., Yangirov, F. N. (2014). Surface hardening for drill pipe life improvement. Oil and Gas Business, 4, 381-399. doi: https://doi.org/10.17122/ogbus-2014-4-381-399

[7] Djukic, L. P., Sum, W. S., Leong, K. H., Hillier, W. D., Eccleshall, T. W., Leong, A. Y. L. (2015). Development of a fibre reinforced polymer composite clamp for metallic pipeline repairs. Materials \& Design, 70, 68-80. doi: https://doi.org/10.1016/ j.matdes.2014.12.059

[8] Afandiyev, E. M., Nuriyev, M. N. (2021). Analysis of the condition of a pipe fixed in a clamping device. EUREKA: Physics and Engineering, 1, 78-85. doi: https://doi.org/10.21303/2461-4262.2021.001587

[9] Markov, O., Gerasimenko, O., Aliieva, L., Shapoval, A. (2019). Development of the metal rheology model of high-temperature deformation for modeling by finite element method. EUREKA: Physics and Engineering, 2, 52-60. doi: https://doi.org/ 10.21303/2461-4262.2019.00877

[10] Bulatov, A. I., Proselkov, Yu. M., Shamanov, S. A. (2003). Tehnika i tehnologiya bureniya neftyanyh i gazovyh skvazhin. Moscow, 1007.

[11] Lopatuhin, I. M. (1989). Razrabotka zazhimnyh ustroystv neftepromyslovogo oborudovaniya s povyshennoy uderzhivayuschey sposobnost'yu. Moscow.

Received date 25.02.2021

(C) The Author(s) 2021

Accepted date 01.04.2021

This is an open access article under the CC BY license

Published date 13.09.2021

(http://creativecommons.org/licenses/by/4.0).

How to cite: Afandiyev, E. M., Nuriyev, M. N. (2021). Analysis of reliability of the drill pipe in the clamping mechanism. EUREKA: Physics and Engineering, 5, 80-87. doi: https://doi.org/10.21303/2461-4262.2021.001765 